\title{
Experiências na adoção de Laboratórios Virtuais para o ensino de Montagem e Manutenção de Computadores
}

\author{
Victor Vieira $^{1,2}$, Antonio Rege dos Santos ${ }^{2}$, Dirceu de Lima ${ }^{2}$, Bruno Gadelha ${ }^{1}$ \\ ${ }^{1}$ Instituto de Computação - Universidade Federal do Amazonas (UFAM) \\ 69.077-000 - Manaus - AM - Brasil
}
${ }^{2}$ Grupo de Informática para Pesquisa em Computação - Instituto Federal do Acre (IFAC) 69.903-068 - Acre - AC - Brasil
\{victor.vieira, antonio.rsantos, dirceu.lima\}@ifac.edu.br, brunodicomp.ufam.edu.br

\begin{abstract}
Educational software is increasingly used by teachers for motivating students to perform an activity. In the case of the virtual laboratories (VLs), the reasons go beyond, involving simulation activities that can be dangerous or expensive. This document describes the use of VLs for teaching disciplines related to maintenance of computers at the Instituto Federal do Acre. The application scenarios of two tools that simulate maintenance laboratories and how teachers adopt these tools in their disciplines are described. An instrument was developed to register the experience with the adoption and analyzed the data obtained to understand the characteristics of this process. The approaches used have several points in common. From the analysis of the notes, it was concluded that it was a motivating factor for the students and, consequently, improve performance. It is suggested that new studies with a greater number, which make possible the classification of data, be carried out for the research.
\end{abstract}

Resumo. Os softwares educativos são ferramentas cada vez mais usadas pelos professores por motivarem os alunos a realizar uma atividade. No caso dos laboratórios virtuais ( $L V S$ ), as questões que justificam o uso vão além, envolvendo a simulação de atividades que podem ser perigosas ou caras. Este documento relata experiências com a adoção de LVS para o ensino de disciplinas relacionadas à montagem e manutenção de computadores no Instituto Federal do Acre. São descritos os cenários de aplicação de duas ferramentas que simulam laboratórios de manutenção e como os professores adotam essas ferramentas em suas disciplinas. Foi desenvolvido um instrumento para registrar a experiência com a adoção e analisados os dados obtidos para entender as características desse processo. Percebeu-se que as abordagens utilizadas possuem diversos pontos em comum. A partir da análise das notas nos três últimos anos e dos relatos dos professores, concluiu-se que a adoção das ferramentas foi um fator motivador para os alunos e, como consequência, resultou em melhorias em suas notas. Sugere-se que novos estudos com amostras maiores, que possibilitem análises quantitativas, sejam realizados para continuidade da pesquisa. 
VII Congresso Brasileiro de Informática na Educação (CBIE 2018)

Anais do XXIV Workshop de Informática na Escola (WIE 2018)

\section{Introdução}

Com o constante surgimento de novas tecnologias que podem ser aplicadas ao ensino, a educação vem se transformando para se adaptar a uma nova geração de alunos, cada vez mais conectados à internet e usuários de vários dispositivos tecnológicos. Os Softwares Educativos (SEs) são uma dessas tecnologias, caracterizados por possuírem uma abordagem diferente para o ensino, se comparados à tradicional sala de aula [Schleyer e Johnson, 2003].

No contexto das atividades de laboratório, uma das ferramentas que está sendo cada vez mais usada são os Laboratórios Virtuais (LVs). Trata-se de uma categoria dos SEs que permite que os estudantes realizem experimentos ou simulem atividades que ocorrem em ambientes físicos através de um dispositivo tecnológico [Lucena, Santos e Silva, 2012]. Entre as vantagens na utilização desse tipo de software educativo, estão [Melo e Osso, 2008]: a) a redução no custo das atividades desenvolvidas, em comparação com como ocorrem no ambiente real; b) a possibilidade de tornar a atividade exclusiva a um aluno, por ser mais fácil individualizar o uso abordando todos os conceitos necessários; e c) a segurança, já que muitas das tarefas realizadas em laboratórios reais podem ser consideradas perigosas.

No Instituto Federal do Acre (IFAC), os LVs foram uma alternativa encontrada por professores de computação para resolver problemas na utilização de laboratórios físicos de Montagem e Manutenção de Computadores. A quantidade de alunos é superior à de equipamentos disponíveis para as tarefas, o que faz com que as atividades em ambiente real tenham que ser desenvolvidas em grupo. Alguns alunos, nesse cenário, ficam desmotivados a interagir. Além disso, várias peças estragam por causa do mau uso, principalmente nas primeiras aulas em laboratório, pois os professores não conseguem acompanhar tudo o que acontece.

Neste trabalho, é apresentado um relato de experiências com o processo de adoção de laboratórios virtuais nas disciplinas Práticas Profissionais em Informática e Manutenção e Suporte em Informática do curso Técnico Integrado ao Ensino Médio em Informática do IFAC. O restante do documento está organizado da seguinte forma: a seção 2 apresenta um referencial teórico sobre LVs e trabalhos relacionados; na seção 3, é descrita a adoção dos LVs; a seção 4 traz os resultados e uma discussão sobre eles; na seção 5 são realizadas as considerações finais e propostos trabalhos futuros; e a última seção mostra as referências utilizadas.

\section{Referencial Teórico}

Os laboratórios virtuais são SEs que permitem que as funções essenciais de experimentos de laboratório sejam realizadas em um dispositivo tecnológico, fora do ambiente real [Sancristobal et al., 2012]. Por se tratarem de um tipo de software educativo, são programas com características pedagogicamente sustentáveis que podem ser utilizado como auxiliares no ensino [Godoi, Padovani e Haracerniv, 2009].

Entre as características dos LVs, destaca-se que [Boehringer, 2009]:

- As experiências podem ser facilmente reproduzidas; 
VII Congresso Brasileiro de Informática na Educação (CBIE 2018)

Anais do XXIV Workshop de Informática na Escola (WIE 2018)

- As simulações podem ser configuradas de forma mais variável do que experiências práticas;

- As simulações podem fornecer situações experimentais não observáveis na realidade;

- Experiências podem ser realizadas com baixo custo e menos complexidade;

- Experiências consideradas perigosas em ambiente real podem ser realizadas de forma segura.

A utilização dessas ferramentas tem gerado uma série de oportunidades de pesquisa e melhorias para o ensino, como as descritas a seguir:

- Wyk e Ryneveld [2017] buscaram melhorar um programa que simula o processo de registro de ocorrências clínicas em laboratórios acadêmicos de Medicina Veterinária a partir da análise da experiência dos usuários no uso da ferramenta. Para isso, realizaram entrevistas com um pequeno grupo de usuários e geraram um questionário para uma avaliação mais completa. O questionário foi aplicado a 133 alunos, que destacaram que a experiência com a ferramenta não foi favorável, no geral, mas se certos aspectos fossem corrigidos, eles considerariam usá-la;

- Diwakar et al. [2016] realizaram uma análise comparativa sobre o papel efetivo de atividades envolvendo laboratórios virtuais em experiências de biotecnologia. 250 alunos e 100 professores participaram do estudo utilizando uma ferramenta e, em seguida, responderam a questões que permitem visualizar a utilidade do software. Os dados analisados indicaram LVs como uma plataforma de educação complementar para alunos e professores para compreender os conceitos dos experimentos, portanto, válida;

- Tsiopela e Jimoyiannis [2017] desenvolveram uma ferramenta web com o objetivo de auxiliar no desenvolvimento de estudantes com autismo e apoiá-los para desenvolver habilidades específicas. O sistema foi avaliado, inicialmente, por especialistas através de um questionário específico sobre aspectos pedagógicos e técnicos da ferramenta. Em seguida, melhorias foram realizadas a partir das opiniões dos especialistas. Concluíram que esse tipo de ambiente pode ajudar os alunos com autismo a adquirir habilidades pré-profissionais e de emprego;

- Nunes et al. [2017] apresentam um mundo virtual criado na plataforma OpenSim para auxiliar no processo de ensino de Geografia no ensino fundamental. $\mathrm{O}$ experimento buscou averiguar a viabilidade da proposta de um Mundo Virtual para complementar o ensino na área de Geografia, apresentando uma análise qualitativa do experimento, expondo a opinião e avaliação dos participantes, sem adentrar no mérito de sua efetividade no quesito avaliação da aprendizagem. Segundo os autores, os resultados opinativos de 72 estudantes do ensino fundamental refletiram que a abordagem foi válida e pode ser utilizada como um recurso complementar em disciplinas desta área neste nível de ensino.

A partir de uma Revisão Sistemática da Literatura sobre registro de experiência de uso de laboratórios virtuais, foram encontrados poucos relatos de experiências 
VII Congresso Brasileiro de Informática na Educação (CBIE 2018)

Anais do XXIV Workshop de Informática na Escola (WIE 2018)

recentes na adoção deles, além dos trabalhos descritos, e a maioria deles para o ensino de Química, Física e Medicina. Poucas características das metodologias desses relatos podem ser utilizadas para Computação. Assim, este trabalho supre essa lacuna relatando uma experiência no processo de adoção de LVs para o ensino de montagem e manutenção de computadores, podendo servir como referência para trabalhos futuros.

\section{Metodologia}

Este relato parte da perspectiva de dois professores de Computação do IFAC que lecionaram em 2017 as disciplinas Práticas Profissionais em Informática e Manutenção e Suporte em Informática, cada um docente de turmas diferentes de $1^{\circ}$ ano do curso Técnico Integrado ao Ensino Médio em Informática da instituição. São disciplinas anuais com carga horária total de 60 horas. Os professores optam por utilizar LVs em suas disciplinas devido às vantagens destacadas nas seções anteriores.

Apesar da iniciativa dos docentes, não há uma padronização quanto à adoção dessas ferramentas nas disciplinas, já que não estão inseridas nas matrizes dos cursos. A instituição não interfere quanto ao uso, nem recomendando, nem reprovando a utilização, e aprovou os Planos de Cursos apresentados por ambos, informando que adotariam ferramentas educacionais para suporte às atividades laboratoriais. Os professores tiveram total liberdade para planejar como realizariam a adoção do software escolhido em suas disciplinas.

A escolha das ferramentas não é amplamente discutida nesse trabalho, mas levou em consideração o fato de os professores já conhecê-las e terem utilizado em outras oportunidades, além da facilidade de uso e de estarem disponíveis gratuitamente e em português. Foram utilizados dois LVs: a) Intel Simulador de Defeitos (INTEL, 2011), um simulador desenvolvido pela Intel baseado em perguntas e respostas sobre um defeito de computador; e b) Cisco IT Essentials Virtual Desktop PC \& Laptop (CISCO, 2008), um simulador desenvolvido pela Cisco que permite ao usuário realizar procedimentos com hardware, como encaixar um processador em uma placa-mãe, por exemplo, em um ambiente seguro. A Figura 1 mostra a interface das ferramentas.

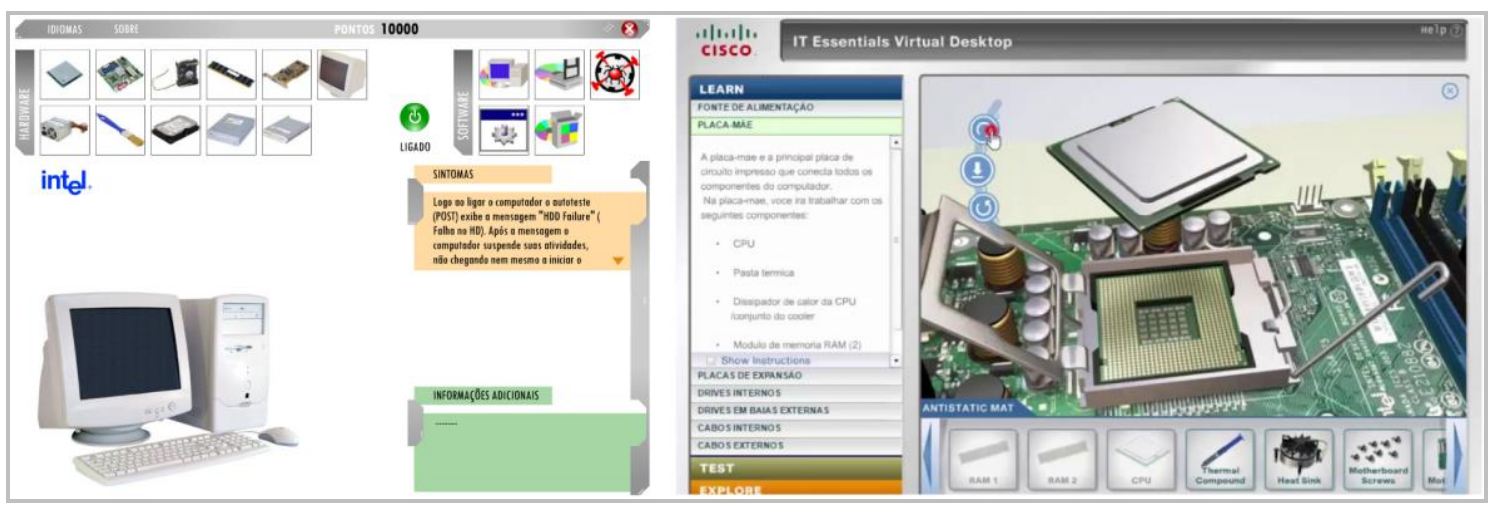

Figura 1. Interfaces do Intel Simulador de Defeitos (esquerda) e do Cisco IT Essentials Virtual Desktop PC \& Laptop (direita)

$\mathrm{Na}$ ferramenta da Intel, o usuário é desafiado a identificar o hardware que precisa ser substituído ou software que precisa ser executado a partir de um "sintoma" (problema) apresentado, que pode vir acompanhado de informações adicionais ou não. 
VII Congresso Brasileiro de Informática na Educação (CBIE 2018)

Anais do XXIV Workshop de Informática na Escola (WIE 2018)

Cada interação gera uma pontuação e a dificuldade aumenta à medida que o usuário acerta. $\mathrm{Na}$ ferramenta da Cisco, o objetivo é montar todos os componentes de um computador de mesa, desde a placa-mãe. A ferramenta informa problemas na compatibilidade dos slots, na posição dos encaixes e outros, à medida que o usuário interage. Vários testes também podem ser realizados no decorrer do uso.

Na turma de Práticas Profissionais em Informática, que utilizou o software da Intel por duas semanas, 40 alunos realizaram 6 horas de atividades na ferramenta. Já a turma de Manutenção e Suporte em Informática utilizou o software da Cisco durante uma semana, com 32 alunos realizando 4 horas de atividades na ferramenta. Os dois LVs formam instalados nos computadores do Laboratório de Informática da instituição, mostrado na Figura 2.

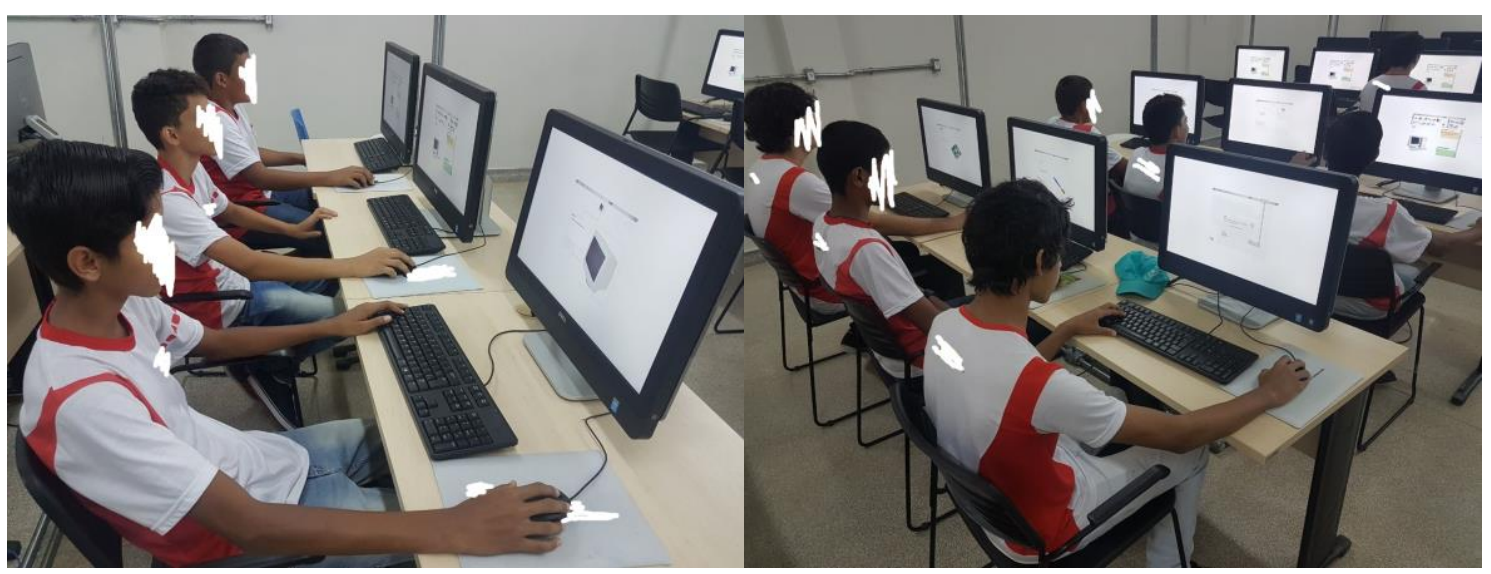

Figura 2. Atividades com os LVs no Laboratório de Informática do IFAC

Este relato descreve as percepções na perspectiva dos professores sobre a adoção dos LVs como alternativa à utilização de laboratórios físicos. Eles foram submetidos ao preenchimento de um questionário desenvolvido exclusivamente para registrar como ocorreram as atividades na adoção das ferramentas em suas disciplinas. $\mathrm{O}$ questionário, mostrado na Tabela 1, foi aplicado ao término dos trabalhos com os LVs e foi respondido em cerca de 30 minutos por ambos. As questões foram desenvolvidas levando-se em consideração os trabalhos de Wyk e Ryneveld [2017] e Diwakar et al. [2016], bem como os pontos considerados necessários para se obter uma visão ampla da adoção. 
VII Congresso Brasileiro de Informática na Educação (CBIE 2018)

Anais do XXIV Workshop de Informática na Escola (WIE 2018)

\section{Tabela 1. Questionário para o registro de experiência de adoção de laboratório virtual com respostas}

\begin{tabular}{|c|c|c|c|c|c|}
\hline & Questões & Objetivos & Respostas possíveis & $\begin{array}{l}\text { Respostas com o Intel } \\
\text { Simulador de Defeitos }\end{array}$ & $\begin{array}{c}\text { Respostas com o Cisco IT } \\
\text { Essentials Virtual Desktop } \\
\text { PC \& Laptop } \\
\end{array}$ \\
\hline \multirow[b]{2}{*}{$\stackrel{\mathscr{B}}{\mathscr{D}}$} & $\begin{array}{l}\text { Q1 - Cada aluno teve } \\
\text { acesso individual ao } \\
\text { LV? }\end{array}$ & $\begin{array}{l}\text { Descobrir se os alunos utilizaram } \\
\text { a ferramenta sozinhos, com maior } \\
\text { carga horária individual de uso }\end{array}$ & $\begin{array}{l}\text { Sim, não ou } \\
\text { parcialmente }\end{array}$ & Sim - uso individual & Sim - uso individual \\
\hline & $\begin{array}{l}\text { Q2 - Com relação ao } \\
\text { espaço de tempo da } \\
\text { disciplina, foi } \\
\text { utilizado... }\end{array}$ & $\begin{array}{l}\text { Descobrir em qual parte da } \\
\text { disciplina a ferramenta foi } \\
\text { adotada }\end{array}$ & $\begin{array}{l}\text { No início, entre o } \\
\text { início e o meio, no } \\
\text { meio, entre o meio e } \\
\text { o fim, no fim }\end{array}$ & Usado no meio da disciplina & $\begin{array}{l}\text { Usado entre o início e o } \\
\text { meio da disciplina }\end{array}$ \\
\hline \multirow{3}{*}{ 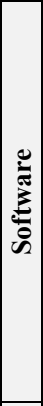 } & $\begin{array}{l}\text { Q3 - Foi } \\
\text { instalado/acessado } \\
\text { facilmente? }\end{array}$ & $\begin{array}{c}\text { Descobrir se houve algum } \\
\text { problema para preparar o } \\
\text { ambiente para o uso da ferramenta }\end{array}$ & $\begin{array}{c}\text { Sim, não ou } \\
\text { parcialmente }\end{array}$ & Sim - instalado facilmente & Sim - instalado facilmente \\
\hline & $\begin{array}{l}\text { Q4 - Imita um } \\
\text { experimento } \\
\text { exatamente como } \\
\text { acontece em um } \\
\text { laboratório real? }\end{array}$ & $\begin{array}{l}\text { Descobrir se a ferramenta possui } \\
\text { um bom nível de fidelidade com a } \\
\text { tarefa a qual se propõe a simular }\end{array}$ & $\begin{array}{l}\text { Sim, não ou } \\
\text { parcialmente }\end{array}$ & $\begin{array}{c}\text { Sim - imita a atividade como } \\
\text { no ambiente real }\end{array}$ & $\begin{array}{c}\text { Sim - imita a atividade como } \\
\text { no ambiente real }\end{array}$ \\
\hline & $\begin{array}{l}\text { Q5 - Possui manual } \\
\text { fácil de ser acessado? }\end{array}$ & $\begin{array}{c}\text { Descobrir se a ferramenta fornece } \\
\text { algum mecanismo de suporte ao } \\
\text { aluno durante o uso }\end{array}$ & $\begin{array}{l}\text { Sim, não ou } \\
\text { parcialmente }\end{array}$ & $\begin{array}{l}\text { Parcialmente - o manual } \\
\text { não está disponível na } \\
\text { própria ferramenta, mas pode } \\
\text { ser acessado na internet } \\
\end{array}$ & $\begin{array}{c}\text { Sim - manual fácil de ser } \\
\text { acessado }\end{array}$ \\
\hline \multirow{3}{*}{ 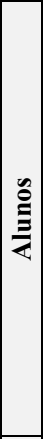 } & $\begin{array}{l}\text { Q6 - Foram } \\
\text { instruídos sobre } \\
\text { como utilizar o } \\
\text { software antes de ter } \\
\text { contato com ele? } \\
\end{array}$ & $\begin{array}{l}\text { Descobrir se o professor forneceu } \\
\text { informações sobre a ferramenta } \\
\text { aos alunos antes da prática }\end{array}$ & $\begin{array}{l}\text { Sim, não ou } \\
\text { parcialmente }\end{array}$ & $\begin{array}{l}\text { Sim - alunos instruídos } \\
\text { anteriormente sobre como } \\
\text { utilizar a ferramenta }\end{array}$ & $\begin{array}{c}\text { Não - alunos não instruídos } \\
\text { anteriormente sobre como } \\
\text { utilizar a ferramenta }\end{array}$ \\
\hline & $\begin{array}{l}\text { Q7 - Tiveram acesso } \\
\text { ao conteúdo } \\
\text { abordado pelo } \\
\text { software antes do } \\
\text { uso, em aulas? }\end{array}$ & $\begin{array}{c}\text { Descobrir se os alunos conheciam } \\
\text { o conteúdo abordado pela } \\
\text { ferramenta antes da prática }\end{array}$ & $\begin{array}{l}\text { Sim, não ou } \\
\text { parcialmente }\end{array}$ & $\begin{array}{c}\text { Sim - conteúdo abordado na } \\
\text { ferramenta ministrado em } \\
\text { aulas }\end{array}$ & $\begin{array}{l}\text { Sim - conteúdo abordado na } \\
\text { ferramenta ministrado em } \\
\text { aulas }\end{array}$ \\
\hline & $\begin{array}{l}\text { Q8 - Foram } \\
\text { auxiliados durante a } \\
\text { atividade? }\end{array}$ & $\begin{array}{c}\text { Descobrir se os alunos tiveram } \\
\text { suporte do professor, além do } \\
\text { manual, na prática }\end{array}$ & $\begin{array}{l}\text { Sim, não ou } \\
\text { parcialmente }\end{array}$ & $\begin{array}{c}\text { Sim - alunos auxiliados } \\
\text { durante a prática }\end{array}$ & $\begin{array}{l}\text { Sim - alunos auxiliados } \\
\text { durante a prática }\end{array}$ \\
\hline \multirow{5}{*}{ 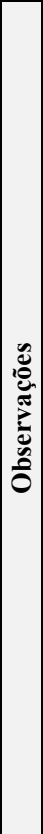 } & $\begin{array}{l}\text { Q10 - A atividade } \\
\text { preparou os alunos } \\
\text { para a prática em } \\
\text { ambiente real? }\end{array}$ & $\begin{array}{l}\text { Descobrir o ponto de vista do } \\
\text { professor sobre o potencial da } \\
\text { ferramenta de preparar os alunos } \\
\text { para a prática em ambiente real }\end{array}$ & $\begin{array}{l}\text { Sim, não ou } \\
\text { parcialmente }\end{array}$ & $\begin{array}{c}\text { Parcialmente - Preparou } \\
\text { parcialmente para a prática } \\
\text { em ambiente real }\end{array}$ & $\begin{array}{c}\text { Sim - preparou totalmente } \\
\text { para a prática em ambiente } \\
\text { real }\end{array}$ \\
\hline & $\begin{array}{l}\text { Q11 - Os resultados } \\
\text { obtidos, quanto ao } \\
\text { ensino, estão... }\end{array}$ & $\begin{array}{l}\text { Descobrir se o professor considera } \\
\text { que a atividade contemplou suas } \\
\text { expectativas no que diz respeito } \\
\text { ao ensino do conteúdo abordado }\end{array}$ & $\begin{array}{c}\text { Abaixo do esperado, } \\
\text { dentro do esperado } \\
\text { ou acima do } \\
\text { esperado } \\
\end{array}$ & Dentro do esperado & Dentro do esperado \\
\hline & $\begin{array}{l}\text { Q12 - Pontos } \\
\text { positivos percebidos } \\
\text { na atividade }\end{array}$ & $\begin{array}{c}\text { Descobrir percepções positivas do } \\
\text { ponto de vista do professor sobre } \\
\text { a atividade }\end{array}$ & Resposta aberta & $\begin{array}{l}\text { Aprendizagem interativa, } \\
\text { necessidade de raciocínio } \\
\text { lógico, software estar } \\
\text { disponível gratuitamente, e } \\
\text { software apresentar } \\
\text { problemas variados } \\
\end{array}$ & $\begin{array}{c}\text { Motivação dos alunos e } \\
\text { abrangência do conteúdo }\end{array}$ \\
\hline & $\begin{array}{l}\text { Q13 - Pontos } \\
\text { negativos percebidos } \\
\text { na atividade }\end{array}$ & $\begin{array}{c}\text { Descobrir percepções negativas } \\
\text { do ponto de vista do professor } \\
\text { sobre a atividade } \\
\end{array}$ & Resposta aberta & $\begin{array}{l}\text { Falta de atualização e } \\
\text { indisponível para web }\end{array}$ & Nenhum ponto negativo \\
\hline & $\begin{array}{l}\text { Q14 - Observações } \\
\text { adicionais }\end{array}$ & $\begin{array}{c}\text { Descobrir outros aspectos } \\
\text { relacionados ao uso da ferramenta } \\
\text { que não tenham sido abordados } \\
\text { nas questões anteriores }\end{array}$ & Resposta aberta & $\begin{array}{c}\text { Nenhuma observação } \\
\text { adicional }\end{array}$ & $\begin{array}{l}\text { Prática em ambiente real } \\
\text { deve ser feita logo após a } \\
\text { simulação }\end{array}$ \\
\hline
\end{tabular}

A escolha de um questionário como instrumento para essa coleta se deu por ser uma ferramenta fácil de ser ministrada e que facilita a análise dos dados [Lakatos e Marconi, 2006]. O instrumento, como mostra a Tabela 1, pode ser dividido em questões: a) gerais sobre o uso; b) sobre o software; c) sobre os alunos; e d) sobre observações do 
VII Congresso Brasileiro de Informática na Educação (CBIE 2018)

Anais do XXIV Workshop de Informática na Escola (WIE 2018)

professor. Apesar de ser composto por questões abertas e fechadas, nas fechadas respondidas com "parcialmente" os participantes puderam justificar a resposta, o que objetivou entender melhor o ponto de vista do docente.

\section{Resultados e Discussão}

A partir dos resultados, percebe-se que as tarefas realizadas possuem mais pontos em comum (sete) que o contrário (quatro), nas onze questões fechadas. Entre eles, destacam-se as ferramentas simularem as atividades como ocorrem no ambiente real, mostrando que são precisas e indicando acerto na escolha, por parte dos professores, e os conteúdos abordados terem sido ministrados em aulas, antes do uso, o que indica uma metodologia similar à que geralmente é aplicada na utilização de laboratórios reais, com a teoria antes da prática. Isso indica que, mesmo não havendo uma padronização quanto à adoção de LVs nas disciplinas, as metodologias utilizadas são similares em diversos aspectos.

$\mathrm{Na}$ experiência com o Intel Simulador de Defeitos, os resultados indicam uma estrutura adequada, com alunos em computadores individuais e devidamente instruídos. Porém, algumas falhas são apontadas na ferramenta, como o manual e a falta de atualização, fazendo com que possa ser considerada ineficiente. A desatualização é um ponto crítico, pois faz com que os conceitos mais atuais da disciplina não possam ser vistos por simulação, tendo que ser trabalhados diretamente no ambiente real ou, num pior caso, somente de forma teórica.

Quanto à experiência com o Cisco IT Essentials Virtual Desktop PC \& Laptop, percebe-se, na visão do professor, uma ferramenta mais robusta, capaz de fornecer preparo total para a prática em ambiente real, sem pontos negativos a serem destacados. Porém, chama atenção o fato de os alunos não terem sido instruídos quanto a como utilizá-la. Comparando a um cenário real, seria como se, ao utilizar um laboratório físico, os alunos pudessem experimentar sem restrições, cometendo vários erros e corrigindo-os. Essa abordagem, baseada em tentativa e erro, apesar de comumente usada com SEs, pode comprometer o aprendizado. Além disso, esse exemplo é descrito na introdução deste relato como um dos problemas que justifica a utilização de LVs.

Para ajudar a verificar se a adoção dos LVs trouxe melhorias para o ensino, foram comparadas as notas das turmas que utilizaram as ferramentas com as de turmas anteriores das mesmas disciplinas, que não tiveram acesso. As notas foram obtidas através dos diários das disciplinas no registro escolar do IFAC de 2015 a 2017 e estão numa escala de 0 a 100 pontos. Os dados estão na Figura 3. 


\section{Práticas Profissionais em Informática}

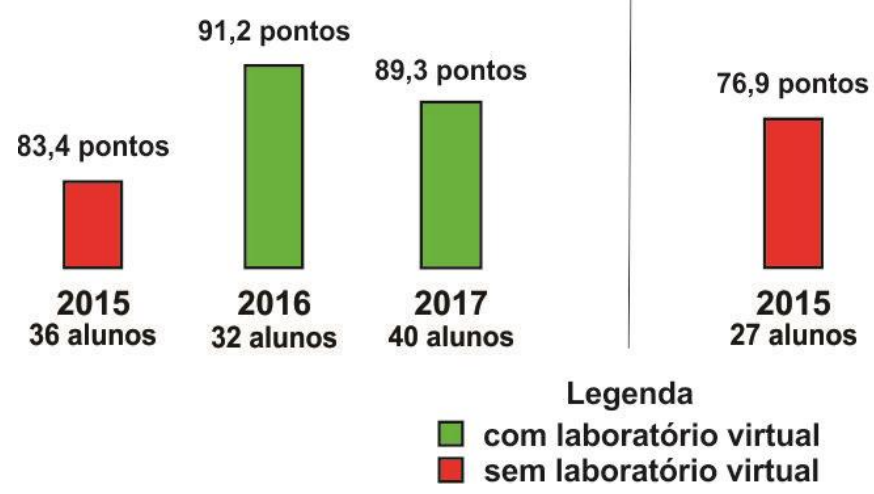

\section{Manutenção e Suporte em Informática}

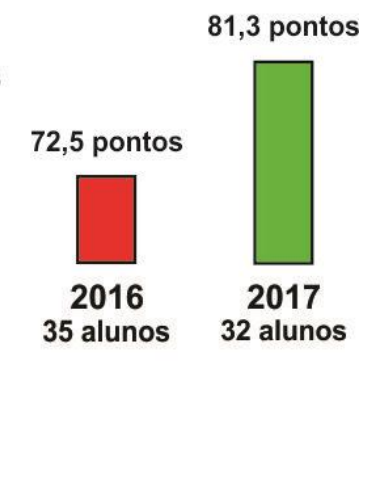

Figura 3. Comparação das notas das turmas com e sem a utilização dos LVs.

Percebe-se que houve melhora no desempenho dos alunos a partir da adoção dos LVs. Na disciplina de Práticas Profissionais em Informática, o aumento foi de 7,8\% em 2016, caindo para 5,9\% em 2017, em comparação com quando o Intel Simulador de Defeitos não foi utilizado, em 2015. Na disciplina de Manutenção e Suporte em Informática, o aumento em 2017, quando foi utilizado o Cisco IT Essentials Virtual Desktop PC \& Laptop, foi de 4,4\% em comparação com 2015 e de 9,8\% em comparação com 2016. Esses números, bem como os relatos dos professores das disciplinas, indicam que a adoção das ferramentas foi um fator motivador para os alunos e, como consequência, resultou em melhorias em suas notas.

Em Práticas Profissionais em Informática, houve uma diminuição de 2016 para 2017 na média das notas, ambas as datas com a utilização do laboratório virtual. Para investigar possíveis causas dessa diminuição, o professor da disciplina foi entrevistado e relatou que a quantidade maior de alunos em 2017 dificultou o acompanhamento e, ainda, alunos reprovados no ano anterior não melhoraram seu desempenho $\mathrm{e}$ prejudicaram o de colegas, considerando esses fatores como relevantes à diminuição das notas.

\section{Considerações finais}

Este trabalho é um resultado parcial de uma pesquisa que trata do registro de experiência docente no uso dos LVs para possibilitar o reuso das ferramentas a partir desses registros. Foi relatado o processo de adoção dos laboratórios virtuais Intel Simulador de Defeitos e Cisco IT Essentials Virtual Desktop PC \& Laptop, respectivamente, nas disciplinas de Práticas Profissionais em Informática e Manutenção e Suporte em Informática do curso Técnico Integrado ao Ensino Médio em Informática do IFAC. Verificou-se que a adoção dessas ferramentas teve um resultado positivo nas notas dos alunos, em comparação com edições anteriores das mesmas disciplinas. Percebeu-se, ainda, com base nos relatos dos professores, uma melhoria na motivação dos alunos durante as atividades e que as ferramentas são uma estratégia importante para situações que envolvam custo ou risco, como, no caso, o de danificar componentes de hardware por mau uso. 
VII Congresso Brasileiro de Informática na Educação (CBIE 2018)

Anais do XXIV Workshop de Informática na Escola (WIE 2018)

As disciplinas contaram com turmas e professores diferentes. Cada adoção foi realizada de acordo com a metodologia de cada professor. Porém, ao analisar os questionários, foi possível observar pontos em comum nas metodologias utilizadas. Esses pontos poderiam ser estudados a fundo, para descobrir que relação têm com a área, por exemplo, ou até mesmo a categoria de SEs abordada.

Reforça-se o fato de que a utilização de softwares educativos torna os alunos mais motivados a aprender e apresenta-se como uma estratégia interessante para a área de computação na abordagem de diversos temas. Espera-se que as informações no documento possam auxiliar outros professores a melhorar as experiências com LVs em suas disciplinas e sejam ponto de partida para novas descobertas.

Como trabalhos futuros, recomenda-se: a) melhorias no instrumento utilizado para registrar a experiência da adoção dos LVs, para que se torne mais completo e seja aplicável a outros cenários; b) pesquisas com amostras que possibilitem análises quantitativas; e c) estudo aprofundado de características em comum, com amostras maiores, na adoção de LVs, para sugerir diretrizes.

\section{Referências}

Boehringer, D.. Dissemination of Remote and Virtual Laboratories for Natural Sciences and Engineering, LiLa - Library of Labs. 2009. Disponível em $<$ http://www.sz.unistuttgart.de/mitarbeiter/burr/lila-bb-2009-06-22-v05.pdf $>$. Acesso em maio de 2018 .

Cisco Systems. Virtual Tools in ITE: PC Hardware and Software v4.0. 2008. Disponível em $<$ https://www.cisco.com/c/dam/en_us/trainingevents/le21/le34/downloads/689/academy/2008/sessions/BRK116T_Virtual_Tools_in_ITEPC.pdf $>$. Acesso em maio de 2018.

Diwakar, Shyam; Radhamani, Rakhi; Sasidharakurup, Hemalatha; Kumar, Dhanush; Nizar, Nijin; Achuthan, Krishnashree; e Nair, Bipin. Assessing Students and Teachers Experience on Simulation and Remote Biotechnology Virtual Labs: A Case Study with a Light Microscopy Experiment. Em: E-Learning, E-Education, and Online Training. Lecture Notes of the Institute for Computer Sciences, Social Informatics and Telecommunications Engineering, volume 160, Springer, 2016.

Godoi, K.; Padovani, S.; e Haracerniv, S.. A prática docente e a seleção de materiais didáticos. A escola e o mundo do trabalho: XVII colóquio afirse secção portuguesa, 2009.

Intel Corporation. Simulador de Defeitos da Intel. 2011. Disponível em < http://docente.ifrn.edu.br/aryalves/disciplinas/semestre-letivo-2015.1/manutencaode-computadores/simulador-de-defeitos-da-intel/view $>$. Acesso em fevereiro de 2018.

Lakatos, E.; e Marconi, M.. Fundamentos de Metodologia Científica. $8^{a}$ ed. São Paulo: Atlas, 2017.

Lucena, Guilherme; Santos, Vandeci; e Silva, Afranio. Laboratório Virtual como alternativa didática para auxiliar o ensino de química no ensino médio. Revista Brasileira de Informática na Educação, Volume 21, Número 2, 2013. 
VII Congresso Brasileiro de Informática na Educação (CBIE 2018)

Anais do XXIV Workshop de Informática na Escola (WIE 2018)

Melo, Roberto; e Osso, João Alberto. Laboratórios virtuais e ambientes colaborativos virtuais de ensino e de aprendizagem: conceitos e exemplos. Em: Revista de Informática Aplicada, volume IV, número 02, 2008.

Nunes, Felipe; Voss, Gleizer; Herpich, Fabrício; Sindeaux, Paulo; Tarouco, Liane; e Lima, José. Implementação e análise de um ambiente 3D para o ensino de Geografia. VI Congresso Brasileiro de Informática na Educação. Anais do XXVIII Simpósio Brasileiro de Informática na Educação, 2017.

Sancristobal, E.; Martín S.; Gil, R.; Orduña, P.; Tawfik, M.; Pesquera, A.; Diaz, G.; Colmenar, A.; GarcíaZubia, J.; e Castro, M.. State of art, Initiatives and New challenges for Virtual and Remote Labs. 12th IEEE International Conference on Advanced Learning Technologies, 2012.

Schleyer, T. and Johnson, L.. Evaluation of educational software. Em: Journal of dental education, volume 67, número 11, 2003.

Tsiopela, D.; e Jimoyiannis, A.. Pre-vocational skills laboratory: designing interventions to improve employment skills for students with autism spectrum disorders. Em: Universal Access in the Information Society, volume 16, 2017.

Wyk, Mari van; and Ryneveld, Linda van. Listening to the student voice to improve educational software. Em: Medical Education Online, volume 22, 2017. 